\title{
Literature Review: Yoga Eye Exercise Effect on Visual Acuity
}

\author{
Muliani \\ Anatomy Department of Medical Faculty of Udayana University, P.B. Sudirman Street, Denpasar, Bali 80232
}

\begin{abstract}
Increased prevalence of myopia has become a worldwide health problem. Progressivity of myopia is increased by digital eye strain. Digital eye strain is a repetitive strain injury and occurs among $70 \%$ computer user. Usually it has strain on the extraocular muscle and a decreased of visual acuity. Digital eye strain should be reduced to improve visual acuity. Yoga and eye exercises can improve visual acuity. Goal of this review paper is to know the effect of yoga eye exercise on visual acuity. It can be concluded that practicing yoga eye exercises for one hour, twice daily in eight weeks will reduce fatigue of the extraocular muscles and improve visual acuity. Further research required to determine the magnitude of improvement of visual acuity due to practicing yoga eye exercises.
\end{abstract}

Keywords: yoga, eye exercise, digital eye strain, visual acuity, extraocular muscles

\section{Introduction}

Advances in technologies such as Android, tablet, computer, internet, and smartphone have brought a positive and negative impact in human life. Some examples of the positive impact are practical, easy and quick to communicate and seek information while farsighted is one example of the negative impact in health.

Recently, the prevalence of farsighted (myopia) was rising to 80-90\% in East and Southeast Asia.[1] Myopia has become a worldwide health problem.[2]

Myopia also affects cognitive function because a good vision is required in obtaining a quick, simultaneous and efficient information.[3] High myopia necessitates a special concern due to its serious complication as macular degeneration, glaucoma, cataract, strabismus, retinal detachments and blindness which ended with the decline of the quality of life.[1],[4]

Myopia can occurred due to seeing digital or computer screen too long and in close distance.[5] This will cause eye strain and accelerate myopia progressivity.[6] Eye complaints due to seeing digital or computer screen, laptop, e-readers, tablet and smartphone too long known as digital eye strain (computer vision syndrome).[7]

Digital eye strain is a repetitive strain injury, occur among $70 \%$ computer user and has occupied the first rank diseases caused by work. The prevalence of digital eye strain was large enough, which is $20.9 \%$ in $2009,30.9 \%$ in 2013 and $42.8 \%$ in 2014 .[8]

Digital eye strain (DES) symptoms are eyes fatigue, dry, strain and irritation, decreased visual acuity, burning sensation, redness, pain around the eyes and double vision.[8]-[13] Burning sensation was experienced by approximately $42.8 \%$ medical and engineer students. [8] This condition is aggravated by pain and strain due to seeing digital screen or computer.[8],[12]

Strain and fatigue should be downgraded to increase vision. It happens by doing eye education, regular exercise, and yoga technique to relax the extraocular muscles and mind so the extraocular eye muscles are trained to see more focus.[13],[14]

Eye exercises often used in vision therapy to relax the eyes, increase visual acuity, prevent and treat myopia without any side effect.[3],[15] Eye exercises which are practiced together with yoga will increase extraocular muscles tone.[16] The aim of this paper is to know yoga eye exercises effect on visual acuity in order to increase public knowledge and improve vision.

\section{Yoga}

Yoga is a technique of exercise which derived from ancient Indian. This includes changes in diet and mental behavior. It trained body posture (yoga asana), regular breathing exercises (pranayama), joint and visual cleansing exercise, relaxation and meditation.[12],[13],[17] Yoga has been known can improve physical and mental health by influencing hypothalamic-pituitary-adrenal axis and sympathetic nervous system.[12]

Some yoga technique like Pranayama, Trataka, and Jala Neti has been suggested to improve vision.[14] Kapalbhati Pranayama enhances fine motor skill and visual discrimination.[18] Hathayoga method teaches harmonization between body and mind through physic and mental cleansing method.[14]

Combination of yoga and relaxation technique can reduce the symptoms of stress and extraocular strain so it can increase visual acuity, eye perception, and blink frequency. Yoga strengthens and prevents the strain of all the extraocular muscles.[12],[13]

Extraocular muscles need to be adjusted, strengthened, stretched and rested in order to maintain focus accurately and clearly. When the body relaxed, muscles became soften and relax so it can return to its normal position and move freely. Vision is an important body function same as mind since eye was brain expansion. As the result of body and mind connection, eye will be relaxed when the mind relaxed. Mind relaxed when it only focus on one thing at a time.[13],[18]

\section{Volume 6 Issue 12, December 2017}




\section{International Journal of Science and Research (IJSR) \\ ISSN (Online): 2319-7064}

Index Copernicus Value (2016): 79.57 | Impact Factor (2015): 6.391

Yoga has been proven to improve the symptoms which occur due to the use of the computer for hours. Yoga practiced for 60 days will reduce uncomfortable feeling of the eyes on 291 computer users. Yoga practiced for 6 weeks is effective to overcome emotion and stress among workers. It increased blood circulation and nutrition to both eyes so improve the health of the eyes. This will relax the extraocular muscle and return the original shape of the eyeball that is important for normal vision.[13]

According to research conducted by Kim, to undergraduate nurses that practiced yoga for 8 weeks, two times daily showed a reduction in extraocular fatigue.[12]

Bansal conducted a clinical trial research on 60 myopia patient $(-6.00 \mathrm{D})$ aged between 8 to 30 years old. Each patients had accompanying symptoms as blur distance vision, difficult to change focus from far to near and vice versa, headache, eye pain, watery, strain and heavy eye. They were divided into two groups. The first group was given Saptamrita Lauha meanwhile yoga was for the other group. Bansal did not find any enhancement in visual acuity although there was a reduction of accompanying symptoms, especially on yoga group. Yoga can relax the mind and mental, increase blood circulation and oxygen supply, brain function and strengthen the extraocular muscles.[14]

\section{Eye Exercise}

Eye exercises method first introduced by William H. Bates in the early 1900's. Bates was an ophthalmologist. This method was known as Bates Method. In his theory, Bates said that myopia and presbyopia caused by tension so relaxation technique can be used to treat myopia and presbyopia. When eyes were in relaxation, they return to their normal function.[19]

Eye exercises can reduce eye's movement disorder, accommodation dysfunction, amblyopia, learning disabilities, dyslexia, asthenopia, myopia, motion sickness, sports performance, stereopsis, visual field defects, increase visual acuity and general health.[4],[19] Myopia can be prevented and treated effectively without any complication by practicing the extraocular muscles.[20]

Eye exercises also improve cognitive function and neural activity by increasing the mechanical plasticity in short-term at superior colliculus, frontal and parietal part of the brain. Those parts of the brain have a role in visual attention, preparatory motor signaling from visuomotor system and working memory (oculomotor circuits).[4]

Mohammed SAAR, found an increase in visual acuity of 15 female students in Saudi, aged 12-15 years old which suffered myopia. They were given eye exercises program for six weeks, which was conducted at school and home. Palming, swinging and central fixation techniques were performed at school while looking into the forehead, nose, right shoulder and left shoulder with fixed head were done at home. Palming and swinging techniques were performed with glasses. Each exercises technique at school done for one minute and repeated three times with break interval 30 seconds between each. Total time required was 13-15 minutes. Technical exercises at school carried out twice a week, on Sunday and Tuesday. At home, technical exercises done for half a minute followed with half a minute break. Break interval conducted with closed eyes then warmed them by rubbing the palm and put them in front of the closed eyes. Home exercises were done twice a day, before learn and sleep, without glasses. Each technique carried out for one minute, repeated three times with 30 seconds break interval. Eye exercises are effective to treat myopia due to its simple, cheap, short-term therapy and reduced the symptoms of myopia.[19]

Insignificant improvement of visual acuity, accommodation and convergence reserve has been found on research done by Ciumbaraite et al., on 15 children age 9 to 18 years old with myopia or pseudomyopia. Those children were given eye exercises for two weeks (ten days).[15]

The extraocular muscles trained by stretching the eyes (move eyes as far as possible with fixed head). There are six steps to stretch the extraocular muscles, that is: moved the eyes from right to left, top to bottom, upper right to lower left, upper left to lower right, make a circle clockwise and counterclockwise until eyes are a little bit tired. On the sixth step, tightly closed the eyes then opened them again. Next, moved the eyes and look at the base of the nose. Then on the final step, moved the focus of the eyes from near to distance object and so on. Each step is repeated for 10 times, three times a day in four weeks without using glasses.[3]

Kang MT has been reported an increase in visual acuity due to the exercise of the extraocular muscle. He concluded that good quality practice of the extraocular muscles in children will delay myopia progressivity.[21]

\section{Yoga Eye Exercise}

According to researched by Gosewade et al., there is a significant increase of visual acuity on patient who was doing Pranayama Kapalbhati together with eyes relaxation exercises.[13]

The following is yoga eye exercise with Pranayama Kapalbhati techniques:[13],[18] Palming and visualizing with Kapalbhati, blinking, near and far focusing with Kapalbhatti, shifting with Kapalbhati, splashing.[13]

Shavasana Yoga (corpse pose) technique was a little bit different with Kapalbhati Pranayama, that is: palming, blinking, sideways viewing, front and sideways viewing, rotational viewing, up and down viewing, preliminary nosetip gazing, near and distant viewing etc. Each step practiced for 5 minutes at a time. Shavasana yoga practiced for 20 minutes after exercised the extraocular muscles to relax it. Palming causes relaxation and revitalization the extraocular muscles, improve circulation at aqueous humor and increase visual acuity.[12] Blinking can increase spontaneous blinking reflex, induction the relaxation muscle of the eyes, prevent irritation and dryness of the eyes.[7],[12] Sideways viewing useful for relaxation of the extraocular muscles which strain due to reading and doing close distance activity, preventing and fixing strabismus. Front and sideways viewing increase both eyes coordination. Up and down

\section{Volume 6 Issue 12, December 2017}




\section{International Journal of Science and Research (IJSR) \\ ISSN (Online): 2319-7064}

Index Copernicus Value (2016): 79.57 | Impact Factor (2015): 6.391

viewing made rectus superior and inferior muscles became balance. Preliminary nose-tip improved accommodation and focus on the muscles of the eyes. Near and distant viewing likewise as nose tip preliminary but the range of movement is greatly improved.[12] Look at a far distance can relax extraocular muscles. Break interval and good quality picture also reduce fatigue of the extraocular muscles [7]. Researched conducted by Harnookar and rukmani on 30 subjects aged 15-25 years old who suffered low-grade myopia $(-0.25 \mathrm{D}$ to $2.00 \mathrm{D})$. They were divided into three groups. Ayurvedic is for the first group while the second group is practiced the extraocular muscles in 15 minutes along with yoga and Ayurvedic and extraocular muscles practiced in 15 minutes along with yoga are for the last group. The therapy gave for eight weeks to each group. The results obtained an enhancement in visual acuity and reduced of other visual symptoms especially in the last group. Yoga and eye exercises practiced can improve extraocular muscles tone.[16]

Practiced of extraocular muscles has been done on 177 myopia patients aged between 4 to 56 years old. These include stretching, stimulating and relaxing with yoga and meditation. This method requires concentration and relaxation. Things that are trained such: eye focus, imagination, eye movement and relaxation (splashing, palming, vapor and cold pack). The practiced include sunning, swaying, swinging, shifting and palming. Practiced should be done for one hour, twice daily (morning and evening). On relaxation phase, the patient asked to focus on counting to ensure the mind was calm. Lekshmi concluded that early detection and relaxation practiced of the extraocular muscle should increase visual acuity in both eyes significantly so it is very effective for myopia patient.[6]

Further research is needed to know the magnitude increase of the visual acuity after yoga eye exercises.[6]

\section{Conclusion}

Yoga eye exercises for one hour, twice daily in eight weeks can reduce fatigue of the extraocular muscles and improve visual acuity.

\section{References}

[1] Muliani. Visual Acuity Stability Of Ortho-K Treatment In A Child With Low Myopia: A Case Study. IJSR 2017; 6(1): 318-20.

[2] Ming M, Scheiman M., Su C., Chen X. Effect of Vision Therapy on Accommodation in Myopic Chinese Children. Journal of Ophthalmology 2016.

[3] Noto PD., Uta S., DeSouza JFX. Eye Exercises Enhance Accuracy and Letter Recognition, but Not Reaction Time, in a Modified Rapid Serial Visual Presentation Task. PLOS ONE 2013; 8(3)

[4] Rathod VJ., Desai DP., Alagesan J. Effect of Eye Exercises on Myopia - Randomized Controlled Study. Journal of Pharmaceutical and Biomedical Studies 2011; 10(12)

[5] Haughton C., Aiken M., Cheevers C. Cyber Babies: The Impact of Emerging Technology on the Developing Infant. Psychology Research 2015; 5(9): 504-18
[6] Lekshmi K. Chronological Age and Subjective Perception of Visual Acuity Among Myopic Patient Practicing Eye Relaxation. European Academic Research 2015; 3(3): 2818-32.

[7] Seegehalli PJ. Digital Eye Strain Reduction Techniques: A Review. IJCSE 2016; 8(30): 94-100

[8] Akinbinu TR. And Mashalla YJ. Impact of Computer Technology on Health: Computer Vision Syndrome (CVS). AcademicJournals 2014; Vol 5(3): 20-30.

[9] Gangamma MP., Poonam, Rajagopala M. A Clinical Study on "Computer Vision Syndrome" and Its Management with Triphala eye Drops and Saptamrita Lauha. An International Quaterly Journal of Research in Ayurveda 2010; 31(2): 236-9.

[10] Gosewade NB., Shende VS., Kashalikar SJ. Effect of Various Eye Exercise Techniques along with Pranayama on Visual Reaction Time: A Case Control Study. Journal of Clinical and Diagnostic Research 2013; 7(8): 1870-3.

[11] Bali J., Neeraj N., Bali RT. Computer Vision Syndrome: A review. Journal of Clinical Ophthalmology and Research 2014; 2(1): 61-8.

[12] Kim SD. Effects of Yogic Eye Exercises on Eye Fatigue in Undergraduate Nursing Students. J. Phys. Ther. Sci 2016; 28: 1813-6.

[13] Gosewade N., Drugkar A., Shende V. Effect of Pranayama and Eye Exercises on Visual Acuity of Medical Students: A Case Control Study. IJCMR 2016; 3(4): 1133-1136

[14] Bansal C. Comparative study on the effect of Saptamrita Lauha and Yoga Therapy in Myopia. An International Quaterly Journal of Research in Ayurveda 2014; 35(1): 22-7.

[15] Ciumbaraite R., Sergejeva O. , Mazeikaite G., Banevicius M., Liutkeviciene R. Eye Exercises Influence on Refractive Error and Reserves of Accomodation and Convergence. Conference "Biomedical Engineering" 2015; 19(1): 89-92.

[16] Harnoorkar VN. And Rukmani. Effect of Isolated and combined Practice of Yoga Therapy and Ayurveda on Distant Vision among Myopia. J Ayurveda and Integr Med Sci 2016; 1(2): 8-12.

[17] Balaji PA., Varne SR. Ali SS. Physiological Effects of Yogic Practices and Transcendental Meditation in Health and Disease. N Am J Med Sci 2012; 4(10): 4428.

[18] Gosewade N., Shende V., Saraf C., Drugkar A. Effect of Pranayama and Eye Exercise on Eye to Hand Coordination: Study By Finger Dexterity Test. J of Evidence Based Med \& Hlthcare 2015; 2(42): 7400-6.

[19] Mohammed SAAR. Vision Therapy-Based Program for Myopia Control in Adolescent. Middle-East Journal of Scientific Research 2013; 13(3): 390-6.

[20] Pandey R., Aranha VP., Samuel AJ. And Kumar SP. A Scoping Literature Review on Effects of Eye Exercises for Myopia in Children. Physiotherapy and Occupational Therapy Journal 2015; 8(1): 27-9.

[21] Kang MT., Ki SM., Peng X. Li L., Ran A., Meng B., Sun Y., Liu LR., Li H., Millodot M., Wang N. Chinese Eye Exercises and Myopia Development in School Age Children: A Nested Case-control Study. Scientific Reports 2016

\section{Volume 6 Issue 12, December 2017}

